\title{
One or two pathways to individual modernity? The effects of education on family formation among women in Japan and Germany
}

\author{
Bernhard Nauck and Rokuro Tabuchi*
}

\begin{abstract}
Two prominent theses on social change concur with regard to the on-going development of family systems in the process of general social change: the model of the "second demographic transition", suggested by the demographers van de Kaa and Lesthaeghe; and the model of "family change", proposed by the crosscultural psychologist Kağıtçıbaşı. This paper presents an empirical test based on an analysis of family change in Japan, a collectivistic, yet modernised society; and in Germany, a society characterised by 'Western' individualism. Our empirical test is based on 12 cumulated, representative surveys from these two societies, which together cover the family formation processes of 49,983 women born between 1915 and 1985. For both Germany and Japan, we examine the influence of educational inequality on family formation, and explore how it has changed over a period of 60 years, by means of multivariate Cox regression analyses. The two models emphasise different aspects of the change in the family formation process: although the changes point in the direction predicted by the second demographic transition model, the differences between the two societies have remained stable or have even widened, in line with the family change model.
\end{abstract}

\section{Introduction}

Two prominent theses on social change concur with regard to the on-going development of family systems in the midst of general social change: the model of the "second demographic transition" and the model of "family change" (Nauck 2009).

The model of the second demographic transition (SDT): This model was developed by the social demographers van de Kaa (1987) and Lesthaeghe (1983).

\footnotetext{
* Bernhard Nauck (correspondence author), Department of Sociology of Chemnitz University of Technology, 09107 Chemnitz, Germany. Email: bernhard.nauck@soziologie.tu-chemnitz.de

Rokuro Tabuchi, Professor at the Faculty of Human Sciences of Sophia University, Tokyo, Japan.
} 
Its starting point was the "first demographic transition" model, which described the shift in affluent societies from a "high-fertility/high-mortality" to a "lowfertility/low-mortality" stage of equilibrium. The SDT model made the claim that the mechanisms that explained the first demographic transition do not adequately account for the more recent demographic developments in societies adhering to the 'western European marriage pattern'; namely the societies of western, southern and central Europe; and the societies founded by the British in North America and Australia. A comprehensive overview on the state of empirical research was provided by Sobotka (2008) and Lesthaeghe (2010), and a comprehensive evaluation of its theoretical content was made by Coleman (2004). According to the SDT model, a fundamental value change has taken place that has resulted in later marriages, higher divorce rates, increasing proportions of non-marital living arrangements, stable low birth rates and high proportions of lifelong childlessness (Lesthaeghe 2010; Lesthaeghe and Surkyn 2008; Surkyn and Lesthaeghe 2004; van de Kaa 2003, 2004). The model implies-as does modernisation theory - that there is a fixed sequence, with the first demographic transition preceding the second. The theoretical argument is that the first demographic transition is linked to the lower-order needs (Maslow 1954), and is thus an "integral part of a development phase in which economic growth fosters material aspirations and improvements in material living conditions". The second demographic transition, by contrast, is linked to the rise of the higher-order needs: "Once basic material preoccupations, and particularly that of long term financial security, are satisfied via the welfare state, more existential and expressive needs become articulated. These are centred on self-actualisation in formulating goals, individual autonomy in choosing means, and recognition for their realization" (Lesthaeghe and Surkyn 2008:90). A similar change in basic motivation is thought to be reflected in individuals' motivations for becoming a parent (Ariès 1980). In contrast to modernisation theory, however, the explanation for the second demographic transition is almost entirely based on the assumption of cultural diffusion. Structural changes are thought to play only a minor (initial) role. Lesthaeghe and Surkyn (2008) argued, in fact, that even the first demographic transition can "take off at just about any level of economic development, and in strictly rural as well as urban societies"; and that it is "a worldwide phenomenon." Consequently, they expected the second demographic transition to become a matter of subsequent "global diffusion". They identified three different components of this predicted process of cultural diffusion: (a) the contraceptive revolution, which made fertility planning highly efficient and reliable by allowing for the separation of sexual behaviour from conception, delaying parenthood; (b) the sexual revolution, which separated sexual behaviour from marriage; and (c) the gender revolution, which gave women equal access to higher education, and thus also to the labour force, which led to a partial detachment of parenthood from marriage. "This entire ideational reorientation, if not revolution, occurs during the peak years of economic growth, and shapes all 
aspects of the second demographic transition" (Lesthaeghe and Surkyn 2008: 88). As the model is based on information diffusion, and as information diffusion is not confined to specific areas, but can take place wherever modern information technology and mass media are available, the second demographic transition should develop in all societies in which these conditions exist.

The model of family change (MFC): This model was developed by Kağıtçıbaşı (2007) in the mid-1980s. Its baseline was the western perspective on the modernisation of the family, many versions of which had been developed, ranging from the classical sociology of Durkheim (1978), to the structural-functionalism of Goode $(1963 ; 1993)$ to the modernisation theory of Lerner $(1958)$. The central claim of the MFC was that most academic theories and descriptions of family change are informed by the culture of "individualism" in western societies. It therefore proposed an alternative model of family change for collectivistic "cultures of relatedness". The MFC posited a fundamental shift from a familyand-kinship-based utilitarian system of solidarity to a system of close emotional bonds, lifelong relatedness and psychological support (Kağıtçıbaşı 2005, 2006, 2007). The conceptual argument on which the model was based is related to a dimensional distinction between "agency" (a bi-polar variable with the end points "autonomy" [a] and "heteronomy" [b]) and "interpersonal distance" (a bi-polar variable with the end points "separation" [c] and "relatedness" [d]), which allows for the possibility that autonomy does not necessarily entail separation, but may even go together with relatedness. Accordingly, four ideal types of families were construed as a combination of the two dimensions, which resulted in a family model of "independence" (a/c), "psychological interdependence" (a/d), "interdependence" (b/d) and "hierarchical neglect" (b/c); with the last representing an analytical category of no further importance for the development of the argument. With the structural change from poverty to affluence, Kağıtçıbaşı predicted a cultural change for the countries with a culture of relatedness from (economic) interdependence to psychological interdependence. This implies that in these societies marriage rates will remain stably high (but perhaps with delayed timing), divorce rates will remain relatively low and birth rates may be significantly reduced (down to 'the' one child), but that childlessness will not be a choice made voluntarily.

The underlying trend hypothesis of the SDT leads to a straightforward prediction: namely that, with its diffusion, a worldwide convergence in family patterns and fertility behaviour will emerge. In other words, the prediction of the SDT departs explicitly from Kağıtçıbaşı's MFC, which predicts an alternative "second way" of modernisation in the "majority world" of the global population who live in a culture of relatedness. It also departs from the assumptions of Thornton (2005) regarding the increasing variability of family patterns as a consequence of the interaction effect between the diffusion of "developmental idealism" and local cultures. Thus, although it is based on a model of cultural diffusion and not on a model of structural change and its effects, the SDT's 
predictions closely approximate those of classical modernisation theory, to which Lesthaeghe and Surkyn made explicit references when they cited "Goode's 1963 prediction, formulated some 40 years ago, that these transformations were going to happen as a part of an overall demographic revolution"; and when they claimed "that more and more evidence pointing in the direction of the SDT will emerge in the next two decades in many non-Western populations" (Lesthaeghe and Surkyn 2008: 111).

Our study tests the arguments of both models comparatively and empirically, utilising data on family change in Japan and Germany. Germans have historically followed the western European marriage pattern, and Germany one of the most affluent societies in the world; it is also an interesting case because it has one single family culture, but its divided political system created differences in opportunity structures for family formation between 1949 and 1990. Japan was chosen because it belongs to the collectivistic East Asian culture, but has long been industrialised, resulting in high levels individual affluence and on-going access to information through western mass media channels. Thus, Japan has been exposed to the ideas that are theorised to result in the second demographic transition, and is, as Lesthaeghe (2010: 234) observed, an "industrialized and urbanized Asian country" of "direct relevance" for testing basic assumptions of the SDT.

\section{Study design}

The existing empirical descriptions of changes in nuptiality and fertility in both societies have been heavily based on ex-post interpretations of highly aggregated time series. Frequently, these interpretations rely on the theoretical framework of the second demographic transition - not only for Germany, as might be expected, but also for Japan (Shirahase 2000; Atoh et al. 2004; Takahashi 2004; Suzuki 2006; Kumagai 2008; Atoh 2001, 2008). Atoh (2001: 7) examined the "value change hypothesis", which he extrapolated from the second demographic transition perspective, through a review of data on post-war value change "to see if the timing of value change corresponds with the recent changes in norms and behavior in relation to marriage and childbirth in Japan". He concluded that a general shift towards individualism and secularisation cannot be observed, but that, since the mid-1980s, "there has been a tremendous attitudinal change related to women's social and family roles." This change may have contributed to the increase in the proportion of never-married women, which has in turn decreased fertility (Atoh 2001: 1). This approach was also followed by Kaneko et al. (2008), in which they described attitude changes by comparing various cross-sectional surveys from different points in time.

Looking at these highly aggregated time series alone, the social changes in both family formation and family stability may be seen as strong challenges to the 
assertion of the enduring maintenance of a family culture of relatedness in societies in which the primary unit of solidarity is the lineage, and may be taken as preliminary indications that the diffusion of the second demographic transition does not stop at the frontiers of patrilineal societies. However, any conclusion drawn from such time series may be premature. First, the level differences for demographic indicators may remain stable, like the differences in the pace of demographic change; moreover, different speeds of family change-even if change is in the same direction-could widen the differences between patrilineal, collectivistic societies like Japan, and bilinear affinal ones like Germany. Second, better data may well detect theoretically important interaction effects between the diffusion of the ideational aspects of the second demographic transition and local cultural settings, as was envisioned by Thornton (2005); initial empirical evidence for Japan was provided by Rindfuss et al. (2004).

In contrast to the post-hoc interpretations of highly aggregated time series for nuptuality and fertility measures at the country level, and ecological correlations between those measures and other indicators, such as GDP, literacy, value orientations etc.; our approach allows for a more direct test of some central assumptions related to the MFC and the SDT. It is more direct because it analyses the assumptions about social change at the individual level, and thus avoids the risk of ecological fallacy. For example, a strong correlation between the proportion of literacy or higher education of a society and a low fertility rate does not allow us to conclude that better educated women have low fertility. This direct individual-level test is adequate and necessary because the theoretical arguments refer to influences on changes in individual behaviour; namely individual choices in family formation, as has been forcefully expressed, for example, in the "ready-willing-able" (RWA) model of the diffusion of new behaviour inherent in the SDT (Lesthaeghe 2010). It is partial because it includes only women in the analysis and concentrates exclusively on the family formation process, whereas family stability and dissolution, which are also central in the predictions of SDT and MFC, are not analysed. Moreover, it focuses on only one central variable — namely the educational level — while other important variables in both explanations - namely changes in values and orientations - are not taken into account here.

Education is chosen as a crucial moderator variable in the analysis of cohort changes of family formation behaviour in Japan and Germany for both technicalpractical and theoretical reasons.

Technical-practical reasons: Information about the educational level of the respondent is available in practically all relevant surveys, and tools are available to make levels comparable internationally and historically. Moreover, the final educational level of respondents is achieved in the great majority of cases before family formation starts, which resolves causality problems in the case of retrospectively gathered information, as is normally the case in cross-sectional surveys. In principle, an even stronger test of the SDT would have included 
attitudinal measures - such as values, preferences or action norms — instead of or in addition to education. However, if they are not derived from panel surveys, it would be necessary to rely on rather strong 'heroic' assumptions (as many analysts do) that these attitudes are formed in a 'sensitive period' in early adulthood and remain a stable cohort characteristic thereafter, and thus are not (or are only marginally) influenced by period effects or changes in the life course, such as marriage and parenthood.

Theoretical reasons: Education has been considered 'the' key variable of individual modernisation in general, and of family formation in particular. Kravdal and Rindfuss (2008: 855) argued that "education's effect on fertility can operate through four mechanisms (balancing roles, affording children, using knowledge gained in school, and finding a partner)". These four mechanisms are not relevant in the same ways and do not have the same intensity when we are testing the explanations of the SDT and the MFC with regard to changes in family formation behaviour in the two societies. Although some studies have provided empirical evidence of a marriage squeeze among women in both post-war Germany (Klein 1995, 2003) and Japan (Raymo and Iwasawa 2005), especially among better educated women, the mechanism for finding an adequate partner is not considered by either the SDT or the MFC. Instead, the link between education and 'learning' is inherent in both models, as education increases individual options and thus makes life courses more "individualised", according to the SDT; and it increases "agency", according to the MFC. More important are the issues of "balancing roles" with regard to the increasing opportunity costs of having children, especially for better educated women, as women started having more opportunities on the labour market and more options for satisfying their "higher order needs" after society's basic physical survival needs had been met, as was predicted by the SDT. "Affording children" has thus lost its association with securing economic resources through wealth flows from the descendants to the parents (Caldwell 1982), i.e. economic interdependence; instead, increased education may be associated with higher investments in the "quality" of the children, i.e. psychological interdependence, as was predicted by the MFC. Generally speaking, increased education hastens the shift in the value of children for their parents from offering work and insurance utility to providing affective stimulation and dialogical benefits (Nauck 2007).

In addition to looking at these mechanisms, which fall under the heading of the "human capital effect" of education, we should consider the "institution effect" (Blossfeld and Huinink 1991; Blossfeld and Jaenichen 1992; Diekmann 1990), which is related to normatively regulated life course transitions. If these norms dictate (as is the case in both Japan and Germany) that family formation should not start before the end of the educational career, and if educational careers are expanded, we may expect to see a delay in family formation, but not necessarily decreased nuptuality, increased childlessness or decreased family extension. 
Besides the delaying of family formation, which may be due to the institution effect of education, the human capital effect may be expected to increase the variability in the probability and the timing of the family formation process. Whereas the SDT predicts a convergence in the two societies in the delaying and increased variability of family formation in Japan and Germany, the MFC predicts less education-induced variability, i.e. less individualisation in the family formation process among Japanese women than among German women, and the emergence of stable differences between the two societies.

The empirical test is based on pooled data taken from twelve demographic, life course and family surveys from Germany and Japan (Table 1). Detailed information on the respective studies are found in the surveys' study papers and method reports. All of the cross-sectional surveys are representative for the age brackets in the respective country or area. However, they share the problem of sample selectivity due to mortality, especially for the older cohorts. The higher survival rates of healthier individuals may well be associated with marriage and fertility probabilities; thus, unmarried and childless individuals may be underreported. However, it is reasonable to assume that this measurement error is roughly identical for Germany and Japan, as the surveys took place at approximately the same time. Because some surveys do not contain the precise date of the interviews, this was set to the end of the survey year when calculating respondents' ages in order to avoid negative arrival times.

The empirical analysis is laid out in several steps below. First, the available demographic time series studies on marriage and fertility in Germany and Japan are analysed. Second, survival analyses of cohort changes in marriage and fertility are performed in order to estimate the proportions of permanent unmarried or childless women. Finally, a multivariate Cox regression analysis is used to estimate the relationship between family formation and education inequality in the two societies.

For the following analysis, only information for females was extracted from the pooled data set $(n=49,983)$. The women are grouped into seven cohorts, ranging from 1915-1924 (cohort 1920), 1925-1934 (cohort 1930), 1935-1944 (cohort 1940), 1945-1954 (cohort 1950), 1955-1964 (cohort 1960), 1965-1974 (cohort 1970) to 1975-1984 (cohort 1980). The analysis thus covers the family formation processes of women in the two countries for a 70-year period beginning before the Second World War and ending at the start of the 21st century. The analysis includes the entry into a stable relationship, as well as the births of children. 
Table 1:

Description of the surveys included in the analysis

\begin{tabular}{|c|c|c|c|c|c|}
\hline $\begin{array}{l}\text { Name of the } \\
\text { study }\end{array}$ & $\begin{array}{l}\text { Survey } \\
\text { year }\end{array}$ & Country & $\begin{array}{l}\text { Birth cohorts } \\
\text { covered }\end{array}$ & $\begin{array}{l}\text { Sample } \\
\text { Size }\end{array}$ & Reference \\
\hline $\begin{array}{l}\text { German Life } \\
\text { Course and } \\
\text { Social Change } \\
\text { Study (West) }\end{array}$ & 1981-1988 & $\begin{array}{l}\text { West } \\
\text { Germany }\end{array}$ & $\begin{array}{l}\text { 1919-1921, } \\
1929-1931, \\
1939-1941, \\
1949-1951, \\
1954-1956, \\
1959-1961\end{array}$ & 5.591 & $\begin{array}{l}\text { doi: } 10.4232 / 1.2645 \\
\text { doi: } 10.4232 / 1.2646 \\
\text { doi: } 10.4232 / 1.2647 \\
\text { K. U. Mayer (2007) }\end{array}$ \\
\hline $\begin{array}{l}\text { German Family } \\
\text { Survey }\end{array}$ & 1988 & $\begin{array}{l}\text { West } \\
\text { Germany }\end{array}$ & $1923-1970$ & 10.043 & $\begin{array}{l}\text { doi: } 10.4232 / 1.2245 \\
\text { C. Alt (1991) }\end{array}$ \\
\hline $\begin{array}{l}\text { German Family } \\
\text { Survey }\end{array}$ & 1990 & $\begin{array}{l}\text { East } \\
\text { Germany }\end{array}$ & 1914-1974 & 1.952 & $\begin{array}{l}\text { doi: } 10.4232 / 1.2392 \\
\text { Leipziger Institut } \\
(1991)\end{array}$ \\
\hline $\begin{array}{l}\text { German Life } \\
\text { Course and } \\
\text { Social Change } \\
\text { Study }\end{array}$ & 1991 & $\begin{array}{l}\text { East } \\
\text { Germany }\end{array}$ & $\begin{array}{l}1929-1931 \\
1939-1941 \\
1949-1951 \\
1959-1961\end{array}$ & 2.331 & $\begin{array}{l}\text { doi: } 10.4232 / 1.2644 \\
\text { K.U. Mayer (2007) }\end{array}$ \\
\hline $\begin{array}{l}\text { German Family } \\
\text { Formation and } \\
\text { Fertility Survey }\end{array}$ & 1992 & Germany & $1952-1972$ & 10.012 & doi: $10.4232 / 1.3400$ \\
\hline $\begin{array}{l}\text { German Family } \\
\text { Survey }\end{array}$ & 1994 & Germany & 1933-1977 & 10.994 & $\begin{array}{l}\text { doi: } 10.4232 / 1.2860 \\
\text { Bender et al. (1996) }\end{array}$ \\
\hline $\begin{array}{l}\text { 2nd Japanese } \\
\text { Family Survey }\end{array}$ & 1998 & Japan & $1921-1970$ & 6.985 & $\begin{array}{l}\text { Department of Social } \\
\text { Structure Research } \\
(1998)\end{array}$ \\
\hline $\begin{array}{l}\text { German Family } \\
\text { Survey }\end{array}$ & 2000 & Germany & $1943-1985$ & 10.318 & $\begin{array}{l}\text { doi: } 10.4232 / 1.3920 \\
\text { Infratest }(2000)\end{array}$ \\
\hline $\begin{array}{l}\text { 3rd Japanese } \\
\text { Family Survey }\end{array}$ & 2003 & Japan & $1926-1975$ & 6.302 & $\begin{array}{l}\text { H. Nishioka et al. } \\
(2010)\end{array}$ \\
\hline $\begin{array}{l}\text { German Gender } \\
\text { and Generations } \\
\text { Survey }\end{array}$ & 2005 & Germany & $1920-1987$ & 10.017 & $\begin{array}{l}\text { K. Ruckdeschel et al. } \\
\text { (2006); R. Nadieri et } \\
\text { al. (2009) }\end{array}$ \\
\hline $\begin{array}{l}\text { German Family } \\
\text { Panel }\end{array}$ & 2008 & Germany & $\begin{array}{l}1971-1973, \\
1981-1983, \\
1991-1993\end{array}$ & 12.402 & $\begin{array}{l}\text { doi: } 10.4232 / \\
\text { pairfam.5678.3.0.0 J. } \\
\text { Huinink et al. (2011) }\end{array}$ \\
\hline $\begin{array}{l}\text { 4th Japanese } \\
\text { Family Survey }\end{array}$ & 2009 & Japan & $1922-1981$ & 5.203 & $\begin{array}{l}\text { H. Nishioka et al. } \\
(2012)\end{array}$ \\
\hline
\end{tabular}


With regard to entry into a stable relationship, one of the theoretical questions is whether marriage is a fully equivalent life event for the two societies. Whereas unmarried couples are still so uncommon in Japan that they are not even captured in social surveys, including the family surveys used in this empirical analysis, they are very common in Germany, and especially in East Germany. Marriage in Germany is in fact a rather unusual starting point for a stable intimate relationship, whereas non-marital relationships have become increasingly institutionalised and have been legally accepted as an equivalent to marriage. For this reason, both the entry into a first marriage and the first entry into a nonmarital household are treated as identical in the German analysis.

An impression of the validity of the data analysed is provided in Figure 1, in which period- related register data of the National Institute of Population and Social Security Research, Japan, and the Federal Institute of Population Research, Germany, are compared to cohort-related data from the pooled surveys. In order to compare the data adequately, the axis for the cohort data is shifted 25 years to be closer to the mean age for marriage and parenthood.

As both graphs clearly show, the survey data do not differ significantly from register data, which may be taken as an indication that the following results are valid for the description of social change in family formation in both societies, and that pooled individual-level data are a valuable source of analysis, allowing researchers to conduct investigations that would not be possible with aggregate level data alone.

\section{Figure 1:}

Comparison of Register and Survey Data for Women in Japan and Germany

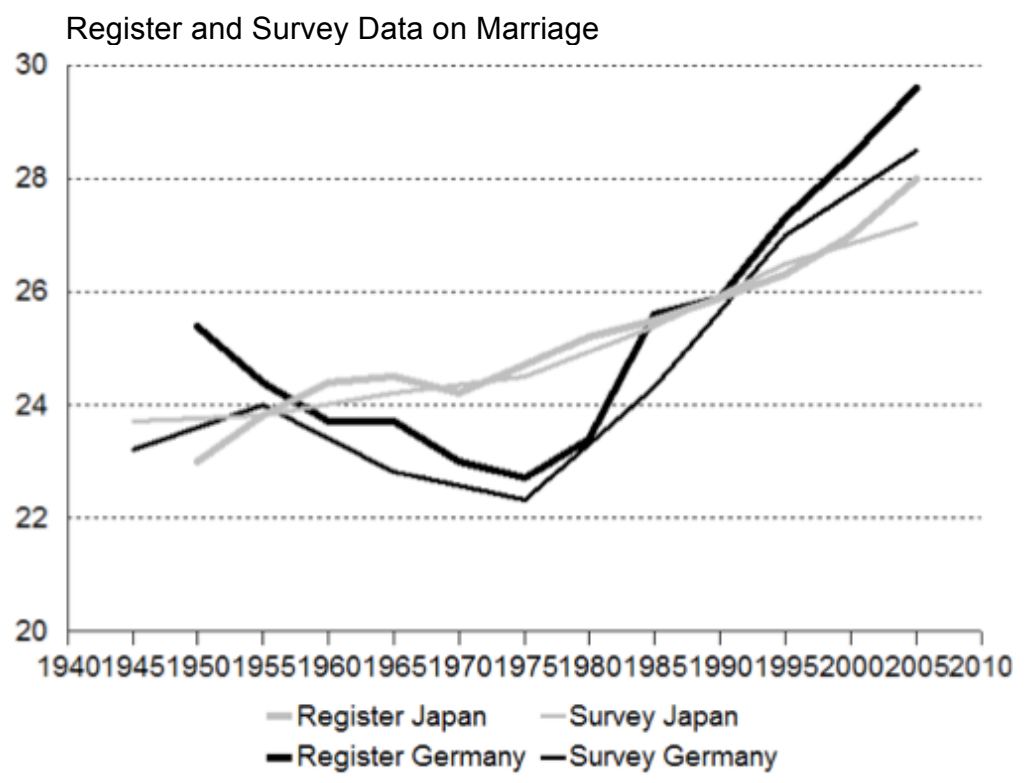




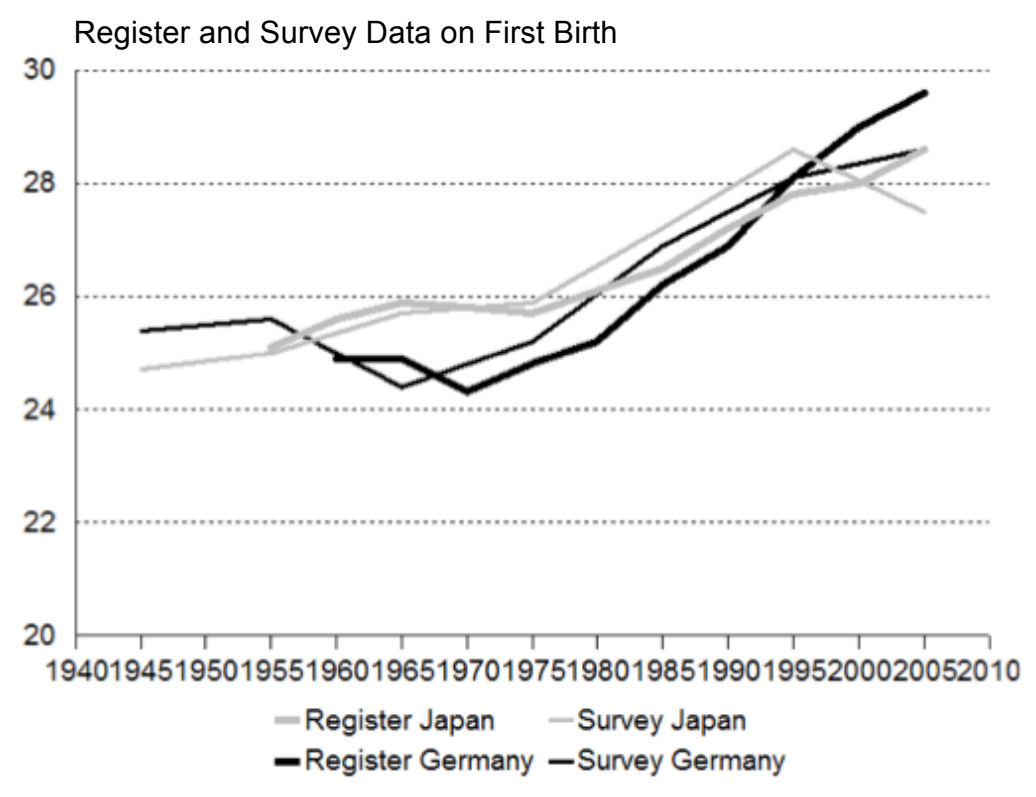

Research questions: (1) Do Japan and Germany converge in having an increased proportion of never-married women, as the SDT predicts; or, alternatively, does this occur only in the individualist society of Germany, while marriage rates remain stably high in the collectivist society of Japan, as the MFC predicts? (2) Do Japan and Germany converge in having an increased proportion of childless women, as the SDT predicts; or, alternatively, does an increased proportion of childless women occur only in the individualist society of Germany, while fertility rates remain stably high in collectivist Japan, as the MFC predicts? (3) With regard to family extension, the MFC and the SDT make very similar predictions in this case. The MFC stresses the change from material to psychological intergenerational interdependence in cultures of relatedness. This is fully compatible with a reduction in fertility to an imprecisely specified level above childlessness. Thus, in general, the MFC would predict higher rates of family extension and less change across generations in Japan, but not in Germany. The SDT stresses that reduced family extension is mainly a phenomenon of the first demographic transition; thus, family extension should have come to an end before the beginning of the value change in the second demographic transition, with the consequent emergence of more individualised life styles and increased childlessness. In other words, the greater prevalence of smaller families should have preceded the value change. But if the assumption of value diffusion holds, then Germany and Japan should converge around lowered rates of family extension in the younger cohorts. (4) To what extent are differences and changes explained by structural factors? If the SDT model is accurate, then the differences in the family formation process between Germany and Japan should narrow over time, as long as structural factors are controlled for, because the cross-national 
diffusion of values and the emergence and increased acceptance of new roles for women should result in a common pattern of family formation. If the MFC model is accurate, then differences in the family formation process between Germany and Japan should remain stable or even increase over time, since behavioural changes are predicted only for the more individualised society of Germany

\section{Cohort changes of marriage and fertility in Germany and Japan}

Table 2 displays the survival times of the seven subsequent decade cohorts in West Germany, East Germany (data from only six cohorts are available) and Japan. For each society and cohort, the ages at which 25 per cent, 50 per cent and 75 per cent of women were married for the first time can be seen. Additionally, the proportion of never-married women or of those who had never lived in a household with a non-marital partner at the age of 40 is displayed (for the last cohort at the age of 30). Also indicated are the $\exp (\mathrm{B})$ from a Cox regression in which the cohorts were entered as dummy variables, with the cohort of 1940 as reference. The 1940 cohort was chosen because it is the first cohort whose family formation process was not influenced by the Second World War. For Germany, the mean age of entry into a household with a non-marital partner and the proportion of women who had never cohabited at the age of 40, are also shown in cases in which this event occurred earlier than marriage.

When compared with the results from the register data in Figure 1, the results from the survey data show an astonishingly coherent picture. The main difference between the two data sources lies in the fact that the register data are much more sensitive to period effects of the respective year of the data collection, whereas the survey data represent cohort effects, which are far less elastic with regard to the timing of the respective event of getting married or entry into parenthood. They are thus far better for the analysis of the effects of socio-cultural changes over time.

Looking at the two oldest cohorts, the results show that the marriage chances of women in both parts of Germany were negatively affected by the Second World War: 20 per cent of the West German women and 21 per cent of the East German women of the birth cohort around 1930 had never been married at the age of 40, whereas in Japan, the marriage rates of the same cohort were not affected. Very different trends between the two societies can be seen for the subsequent cohorts.

In West Germany, the age at which half of all women were married increased steadily from 22.8 years for the 1940 cohort to 28.6 years for the 1980 cohort. Also increasing was the gap between the first and the third quartiles, from less than five years to about ten years. This widening gap may be taken as an indication of increased individualisation from the birth cohort 1940 onwards, and 
One or two pathways to individual modernity?

thus affirms both the model of family change and the model of the second demographic transition

Table 2:

Cohort differences in survival times until first marriage of women in Germany and Japan

\begin{tabular}{|c|c|c|c|c|c|c|c|c|}
\hline \multicolumn{2}{|c|}{ Cohort } & 1920 & 1930 & 1940 & 1950 & 1960 & 1970 & 1980 \\
\hline \multirow{7}{*}{ 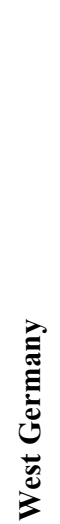 } & $25 \%$ & 20.8 & 21.3 & 20.9 & 20.0 & 22.9 & 21.1 & 23.8 \\
\hline & Median marriage & 23.3 & 24.0 & 22.8 & 22.3 & 27.2 & 24.3 & 28.6 \\
\hline & $75 \%$ & 29.0 & 30.0 & 25.6 & 26.1 & 33.1 & 30.6 & \\
\hline & $\begin{array}{l}\text { Never married at } \\
\text { age } 40\end{array}$ & $13 \%$ & $20 \%$ & $11 \%$ & $11 \%$ & $17 \%$ & $11 \%$ & $47 \%^{1)}$ \\
\hline & $\exp (B)^{2)}$ & $0.81 * * *$ & $0.67 * * *$ & 1.00 & $1.05 *$ & $0.53^{* * *}$ & $0.76 * * *$ & $0.36^{* * *}$ \\
\hline & Median cohabitation & 23.3 & 23.7 & 22.5 & 21.5 & 23.0 & 21.8 & 24.2 \\
\hline & $\begin{array}{l}\text { Never cohabited at } \\
\text { age } 40\end{array}$ & $13 \%$ & $18 \%$ & $6 \%$ & $6 \%$ & $10 \%$ & $7 \%$ & $39 \%^{1)}$ \\
\hline \multirow{7}{*}{ 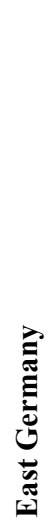 } & $25 \%$ & - & 20.2 & 19.9 & 19.7 & 21.6 & 20.1 & 26.8 \\
\hline & Median marriage & - & 22.6 & 21.8 & 21.4 & 26.4 & 22.0 & 29.9 \\
\hline & $75 \%$ & - & 28.7 & 24.2 & 24.1 & 40.0 & 26.0 & \\
\hline & $\begin{array}{l}\text { Never married by } \\
\text { age } 40\end{array}$ & - & $21 \%$ & $11 \%$ & $10 \%$ & $25 \%$ & $9 \%$ & $69 \%{ }^{1)}$ \\
\hline & $\exp (B)^{2)}$ & - & $0.69^{* * *}$ & 1.00 & $1.08^{*}$ & $0.47 * * *$ & $0.92 *$ & $0.16^{* * *}$ \\
\hline & Median cohabitation & - & 22.0 & 21.4 & 21.0 & 21.7 & 21.1 & 25.1 \\
\hline & $\begin{array}{l}\text { Never cohabited at } \\
\text { age } 40\end{array}$ & - & $17 \%$ & $7 \%$ & $5 \%$ & $13 \%$ & $6 \%$ & $49 \%^{2)}$ \\
\hline \multirow{5}{*}{ 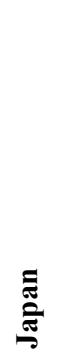 } & $25 \%$ & 23.6 & 22.4 & 22.6 & 22.8 & 24.5 & 23.6 & 25.5 \\
\hline & Median marriage & 23.7 & 23.8 & 24.2 & 24.5 & 27.1 & 25.6 & 29.4 \\
\hline & $75 \%$ & 23.7 & 24.6 & 26.1 & 26.6 & 32.0 & 28.8 & \\
\hline & $\begin{array}{l}\text { Never married at } \\
\text { age } 40\end{array}$ & $4 \%$ & $3 \%$ & $11 \%$ & $10 \%$ & $18 \%$ & $12 \%$ & $48 \%{ }^{1)}$ \\
\hline & $\exp (B)^{2)}$ & $1.56^{* * *}$ & $1.50^{* * *}$ & 1.00 & 0.96 & $0.54 * * *$ & $0.75 * * *$ & $0.35^{* * *}$ \\
\hline
\end{tabular}

Notes: ${ }^{1)}$ at age $30 ;{ }^{2)}$ reference cohort $1940 ; * \mathrm{p}<.05 ; * * \mathrm{p}<.01 ; * * * \mathrm{p}<.001$. 
In East Germany, a curvilinear trend is observed, with a decreased median marriage age - going as low as 21.4 years - until the 1950 cohort, followed by a sharp increase to 29.9 years for the 1980 cohort. This development is paralleled by a widening gap between the first and the third quartiles, from about four years to approximately 18 years. This may be taken as an indication that individualisation had also increased in East Germany.

It is important to note that, if the cohabitation rates are considered, the changes in Germany appear to be far less dramatic. Apart from the impact of the losses of men in the Second World War, which severely reduced the chances of marriage or cohabitation, the overall rates of marriage and cohabitation were relatively high in all of the observed cohorts. We do see, however, a steady loss in the relative importance of marriage, especially in East Germany.

Japan shows, in some respects, a different pattern of change in the marriage rates. The age at which half of all women were married increased steadily from 23.7 in the 1920 cohort to 29.4 in the 1980 cohort. The age gap between the first and the third quartiles was significantly lower than in both parts of Germany, increasing to only 7.5 years in the 1970 cohort. In addition, the proportion of never-married women in most cohorts was much lower than in Germany, but it increased from cohort to cohort. This may be taken as an indication of an increasingly individualised lifestyle among Japanese women, especially in the youngest cohorts.

Table 3 displays the survival times until the birth of the first child for the cohorts in West Germany, East Germany and Japan. As in Table 2, Table 3 displays the survival times until the birth of the first child of seven subsequent decade cohorts in West Germany, East Germany (six cohorts) and Japan. Also displayed are the proportion of women who were childless at the age of 40 (for the last cohort at the age of 30 ) and the $\exp (\mathrm{B})$ from a Cox regression in which the cohorts were entered as dummy variables, with the 1940 cohort as reference.

In both parts of Germany, a curvilinear trend appears for the entry into motherhood.

In West Germany, the age at which half of all women had given birth at least once, decreased until the 1940 cohort, and then increased steadily from 24.4 years to 27.4 years for the 1980 cohort. In addition, the gap between the first and the last quartiles widened. This, together with the increased proportion of women who were childless at the age of 40 from the 1940 cohort onwards, may be taken as an indication of increased individualisation, and thus as a confirmation of both the MFS and the SDF. 
Table 3:

Cohort differences in the survival times until the birth of the first child of women in West Germany, East Germany and Japan

\begin{tabular}{|c|c|c|c|c|c|c|c|c|}
\hline & Cohort & 1920 & 1930 & 1940 & 1950 & 1960 & 1970 & 1980 \\
\hline \multirow{5}{*}{ 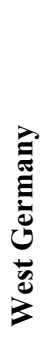 } & $25 \%$ & 22.3 & 22.3 & 21.7 & 22.9 & 21.2 & 23.9 & 23.5 \\
\hline & Median & 25.4 & 25.6 & 24.4 & 26.9 & 25.2 & 28.1 & 27.4 \\
\hline & $75 \%$ & 31.9 & 30.6 & 28.4 & 32.3 & 30.5 & 33.0 & 29.3 \\
\hline & $\begin{array}{l}\text { Childless at } \\
\text { age } 40\end{array}$ & $18 \%$ & $17 \%$ & $12 \%$ & $14 \%$ & $14 \%$ & $15 \%^{1)}$ & $17 \%^{2)}$ \\
\hline & $\exp (B)^{3)}$ & $0.77^{* * *}$ & $0.80^{* * *}$ & 1.00 & $0.73^{* * *}$ & $0.87^{* * *}$ & $0.64 * * *$ & $0.61 * * *$ \\
\hline \multirow{5}{*}{ } & $25 \%$ & & 20.5 & 20.3 & 20.3 & 20.2 & 20.9 & 22.1 \\
\hline & Median & & 22.6 & 22.6 & 22.4 & 22.5 & 23.8 & 26.1 \\
\hline & $75 \%$ & & 25.3 & 25.4 & 25.2 & 25.5 & 29.0 & \\
\hline & $\begin{array}{l}\text { Childless at } \\
\text { age } 40\end{array}$ & & $11 \%$ & $9 \%$ & $9 \%$ & $8 \%$ & $11 \%^{1)}$ & $30 \%^{2)}$ \\
\hline & $\exp (B)^{4)}$ & & 0.95 & 1.00 & 1.03 & 1.00 & $0.74 * * *$ & $0.51 * * *$ \\
\hline \multirow{5}{*}{ 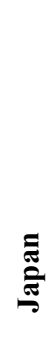 } & $25 \%$ & 22.9 & 22.6 & 23.5 & 24.6 & 23.8 & 25.6 & 25.5 \\
\hline & Median & 24.7 & 25.0 & 25.6 & 27.2 & 25.8 & 28.8 & 30.3 \\
\hline & $75 \%$ & 27.6 & 28.6 & 28.1 & 31.0 & 28.7 & 33.3 & \\
\hline & $\begin{array}{l}\text { Childless at } \\
\text { age } 40\end{array}$ & $15 \%$ & $11 \%$ & $9 \%$ & $14 \%$ & $9 \%$ & $18 \%{ }^{1)}$ & $51 \%{ }^{2)}$ \\
\hline & $\exp (B)^{3)}$ & 1.00 & 1.01 & 1.00 & $0.71^{* * *}$ & 0.95 & $0.54 * * *$ & $0.42^{* * *}$ \\
\hline
\end{tabular}

Notes: ${ }^{1)}$ at age $38 ;{ }^{2)}$ at age $30 ;{ }^{3)}$ Reference: $1940 ;{ }^{*} \mathrm{p}<.05 ; * * \mathrm{p}<.01 ; * * * \mathrm{p}<.001$.

In East Germany, a curvilinear trend is observed, with a decrease in the median age until the 1960 cohort, when it went as low as 22.4 years; followed by a sharp increase to 26.1 years for the 1980 cohort. This development was paralleled by a widening gap between the first and the third quartiles, with a minimum of five years for the 1930 to 1960 cohorts, and a rapid increase in the variance for the entry into motherhood thereafter. This, together with an increased proportion of childless women in the younger cohorts, may be taken as an indication that individualisation had also increased in East Germany.

Japan shows, in some respects, a different family formation pattern. The age at which half of all women had given birth at least once increased from 24.7 in the 1920 cohort to 30.3 in the 1980 cohort. The proportion of childless women 
increased in the two youngest cohorts, as did the age gap between the first and third quartiles.

Like for partnership formation, the family formation process in Japan started later than in Germany. But then, as the results for the Cox regressions show, the Japanese pattern was very similar to that of West Germany, with an increasing delay in parenthood from the 1950 cohorts onwards, and increased rates of permanent childlessness in the youngest cohorts. With regard to the birth of the first child, the main divide was between East Germany on the one hand, and Japan and West Germany on the other. At least for the GDR period, East German women had a highly standardised early family formation process and low rates of permanent childlessness. The impact of political unification was clearly reflected in the 1970 cohort of East German women, among whom a sudden delay in the entry into motherhood and increased childlessness occurred.

Table 4 displays the proportions of women who had given birth to a second child in an interval of ten years after the birth of the first child. It also shows those who had given birth to a third child in an interval of ten years after the birth of the second child. Moreover, the table displays the proportion of women who had given birth to a third child by the age of 40 and the results of the Cox regression, again with the oldest cohort as reference. Because of the rapidly decreasing numbers of cases, the results for higher parity in the youngest cohort are less valid.

The three countries show distinctive developments in family extension.

In West Germany, a modest curvilinear development in the rates of having a second and a third child occurred, indicating that, in the younger cohorts, women who had entered into motherhood were increasingly likely to give birth to additional children. This was confirmed by the Cox regression, which showed increased values for the younger cohorts. The difference in the probability of having another child and the final possible outcome (having a third child at the end of the fertility career) demonstrates the dynamics of social change in the family formation process in West Germany. Although the probability that a mother will have another child soon has been quite high in recent cohorts, the final outcome remains a low-probability event because of the increasing numbers of childless women and the late entry into motherhood.

In East Germany, family extension was always at much lower levels than in West Germany. Generally, two out of three East German women who had given birth to a first child had given birth to a second child within the next 10 years, and one-third of East German women went on to have a third child within 10 years after the second birth.

In Japan, the second-child birth rates were stably high and even increased over time. More than four out of five Japanese women who had given birth to a first child went on to give birth to a second child within the next 10 years. Only small differences separate the cohorts, as the majority of insignificant results in the Cox regression reveals. However, cohort differences for the birth rates for a 
third child are relatively strong, with a marked decrease in third births until the 1940 cohort, and a slight recovery thereafter. In sum, the number of children born to women of a given cohort by the end of their fertility careers was decreasing, as the percentages of women who gave birth to a third child by the age of 40 shows. Whereas about 50 per cent of the 1920 cohort gave birth to a third child, this share declined from the 1940 cohort onwards to around 25 per cent.

Table 4:

Cohort differences in the survival times until the birth of the third child of women in West Germany, East Germany and Japan in quartiles

\begin{tabular}{|c|c|c|c|c|c|c|c|c|}
\hline \multicolumn{2}{|c|}{ Cohort } & 1920 & 1930 & 1940 & 1950 & 1960 & 1970 & 1980 \\
\hline \multirow{5}{*}{ 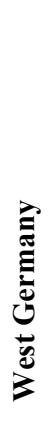 } & $\begin{array}{l}2^{\text {nd }} \text { child } \\
10 y \text { later }\end{array}$ & $63 \%$ & $69 \%$ & $74 \%$ & $67 \%$ & $72 \%$ & $81 \%$ & $86 \%$ \\
\hline & $\exp (B)^{1)}$ & $0.71^{* * *}$ & $0.87 * * *$ & 1.00 & $0.81 * * *$ & $0.93 * *$ & $1.12^{* * *}$ & $1.13^{*}$ \\
\hline & $\begin{array}{l}3^{\text {rd }} \text { child } \\
10 y \text { later }\end{array}$ & $49 \%$ & $47 \%$ & $38 \%$ & $30 \%$ & $37 \%$ & $48 \%$ & - \\
\hline & $\exp (B)^{1)}$ & $1.40^{* * *}$ & $1.31^{* * *}$ & 1.00 & $0.74 * * *$ & 0.95 & $1.22^{* * *}$ & $1.75^{* * *}$ \\
\hline & $\begin{array}{l}3^{\text {rd }} \text { child by } \\
\text { age } 40\end{array}$ & $29 \%$ & $30 \%$ & $28 \%$ & $19 \%$ & $22 \%$ & $22 \%$ & $18 \%^{2)}$ \\
\hline \multirow{5}{*}{ 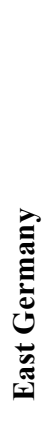 } & $\begin{array}{l}2^{\text {nd }} \text { child } \\
10 y \text { later }\end{array}$ & - & $72 \%$ & $66 \%$ & $66 \%$ & $71 \%$ & $66 \%$ & $70 \%$ \\
\hline & $\exp (B)^{1)}$ & - & $1.20 * *$ & 1.00 & 1.03 & $1.12^{* *}$ & 0.90 & 1.06 \\
\hline & $\begin{array}{l}3^{\text {rd }} \text { child } \\
10 y \text { later }\end{array}$ & - & $32 \%$ & $35 \%$ & $27 \%$ & $27 \%$ & $44 \%$ & $52 \%$ \\
\hline & $\exp (B)^{1)}$ & - & 0.87 & 1.00 & $0.74 * * *$ & $0.74 * * *$ & 1.13 & $1.81 * *$ \\
\hline & $\begin{array}{l}3^{\text {rd }} \text { child by } \\
\text { age } 40\end{array}$ & - & $22 \%$ & $24 \%$ & $19 \%$ & $18 \%$ & $16 \%$ & $5 \%{ }^{2)}$ \\
\hline \multirow{5}{*}{ 苞 } & $\begin{array}{l}2^{\text {nd }} \text { child } \\
10 y \text { later }\end{array}$ & $85 \%$ & $83 \%$ & $84 \%$ & $87 \%$ & $86 \%$ & $87 \%$ & $86 \%$ \\
\hline & $\exp (B)^{1)}$ & 1.08 & 0.97 & 1.00 & $1.13^{* * *}$ & $1.11^{* *}$ & 1.03 & 0.84 \\
\hline & $\begin{array}{l}3^{\text {rd }} \text { child } \\
10 y \text { later }\end{array}$ & $68 \%$ & $40 \%$ & $33 \%$ & $34 \%$ & $39 \%$ & $38 \%$ & $56 \%$ \\
\hline & $\exp (B)^{1)}$ & $2.85^{* * *}$ & $1.35^{* * *}$ & 1.00 & 1.07 & $1.23^{* * *}$ & $1.19 *$ & $1.56^{*}$ \\
\hline & $\begin{array}{l}3^{\text {rd }} \text { child by } \\
\text { age } 40\end{array}$ & $51 \%$ & $31 \%$ & $25 \%$ & $28 \%$ & $28 \%$ & $21 \%$ & $5 \%{ }^{2)}$ \\
\hline
\end{tabular}

Notes: ${ }^{1)}$ reference 1940 cohort; ${ }^{2)}$ at age $30 ; * \mathrm{p}<.05 ; * * \mathrm{p}<.01 ; * * * \mathrm{p}<.001$. 
These findings replicate results from previous research on the spread of cohabitation (Nazio and Blossfeld 2003) and the on-going demographic bifurcation of West Germany into a non-family sector (permanently childless individuals) and a family sector in which two or more offspring prevail and onechild families are relatively rare (Strohmeier and Huinink 2003). They also replicate results for East Germany, where childless women are rare and one-child families are much more frequent, but where family extension has declined (Huinink and Wagner 1995; Kreyenfeld and Huinink 2003). The comparative analysis reveals that Japanese women fall into line with the West German model, but in a more extreme fashion. The general fertility decline in Japan is obviously the result of an increased number of childless women, as a stably high number of Japanese who gave birth to one child went on to have a second child, and in higher proportions in all cohorts relative to German women.

\section{Structural effects on family formation in Germany and Japan}

An analysis of structural effects on family formation in both countries must exclude the possibility that changes in family formation are mostly or entirely attributable to changes in the composition of the population over time. Accordingly, an initial step must be to ask whether increased education results only in a delay in the family formation process attributable to more time spent in formal education, or whether it results in changes in family formation that go beyond the delaying effect. In fact, both Germany and Japan have undergone a significant educational expansion, drawing increasingproportions of the female population into higher education.

In order to control for these effects on the comparison of change in the family formation process across the countries, the following measures were undertaken. Educational level was classified as a rank order according to the ISCED and CASMIN standards. Subsequently, the distribution of the educational level was calculated separately for each sex and cohort in each survey. The educational level was set as the mean percentile of the respective education level within the country's respective cohort. Because measurement differs from survey to survey, this assignment was made for each survey separately. Using this procedure, the educational level across countries and cohorts was standardised. This method allows for the control of the structural effect of educational expansion on social change in family formation, which is the only available variable in cross-sectional data, and which remains largely stable from the beginning of the family formation process onwards. Other variables, such as individual and household income and occupational prestige, were operationalised and tested in the same way, based on the additional assumption that the trajectories of occupational prestige and income of different status groups do not cross during the life course. These showed 
mostly significant effects in the theoretically expected direction, but, since the direction of causality between these factors and family formation is ambiguous (especially in the case of women), they were not included in the multivariate analyses.

In Figure 2, country-specific differences in changes in the family formation processes of Japanese and German women of different educational levels are shown. Members of the lowest 30 per cent and the highest 20 per cent are compared on the dimensions of marriage and birth of first child. Since the educational level variable already controls for effects of educational expansion, the analysis is not biased by the inflation of obtained education degrees over time, but it accounts for educational inequalities within and across cohorts and countries. The graphs in Figure 1 display for each cohort the age at which 25 per cent, 50 per cent, and then 75 per cent of women had made the transition to marriage and to motherhood.

The analysis shows for both societies the expected difference in the timing of family formation, with better educated women consistently starting families later in life than less educated women. This supports the assumptions related to the institution effect. Moreover, the analysis finds that differences in the family formation process between educational strata increased after the 1940 cohort, as did age variability in the transition to both events.

\section{Figure 2:}

Educational levels of women and family formation processes in Japan and Germany

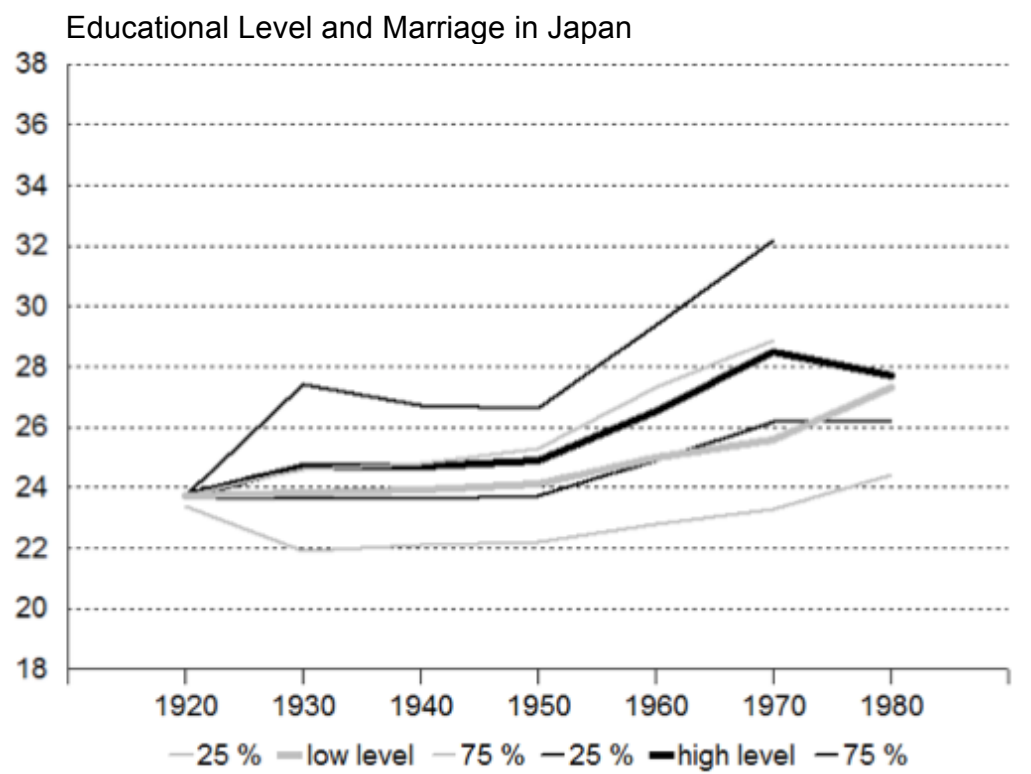




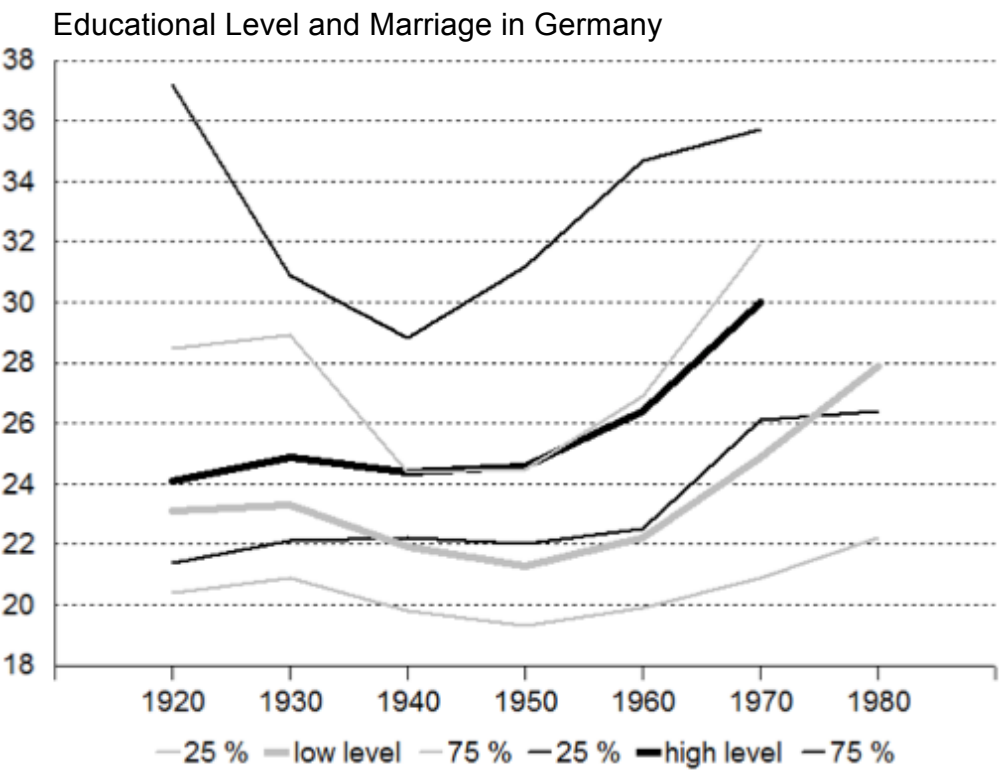

Educational Level and First Birth in Japan

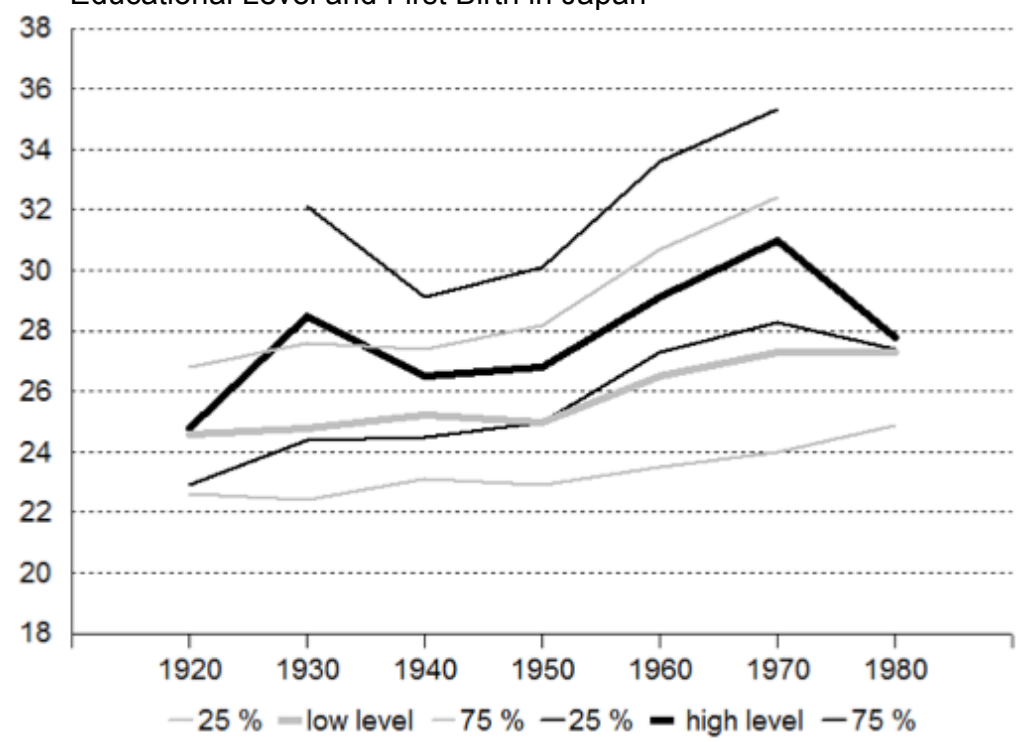




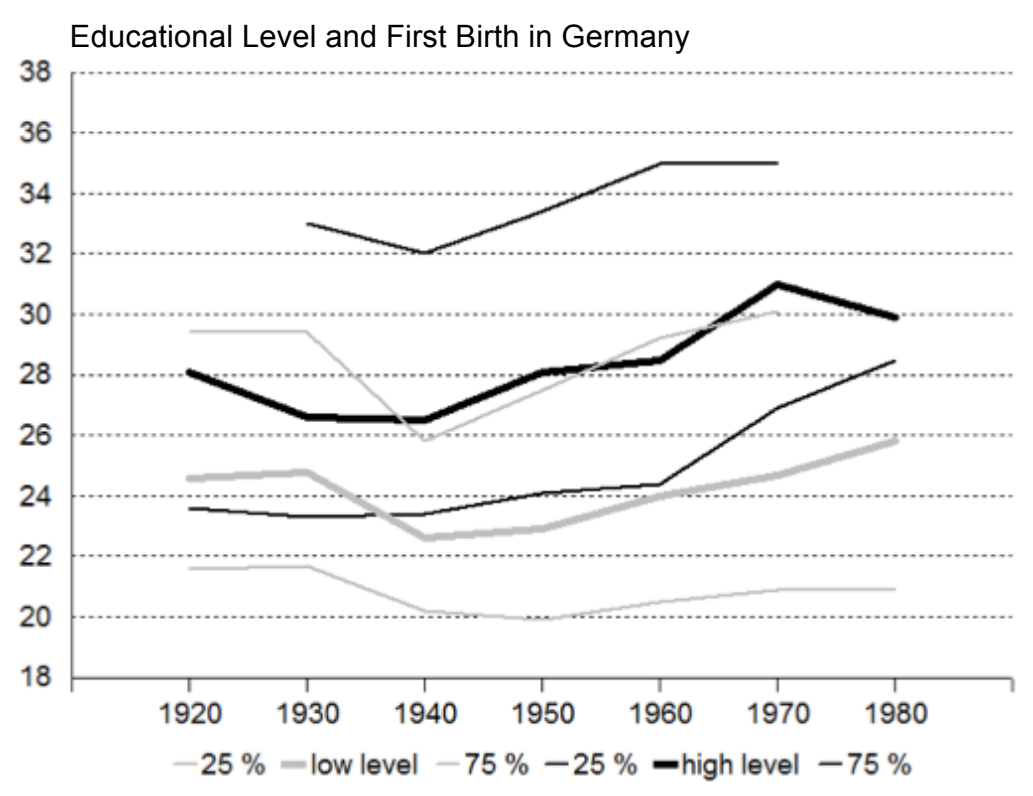

The competing predictions are best tested by observing the interaction effect of education level, cohort and country on the timing of events in the family formation process, again indicated by the entry into the first stable relationship and the births of the first and third children. The results in Table 5 display two Cox regression models, with each including the event of the first cohabitation or the first marriage, the event of the birth of the first child (both with the entire life span as the risk period), and the event of the birth of the third child (with the time since the birth of the second child as the risk period). In the first model, the respective cohort membership (with the 1940 cohort as reference), the country (with Japan as reference), and the percentile of the educational level was entered. In the second model, the interaction effect between cohort and country was also entered.

The results presented in Table 5 are straightforward. The introduction of interaction effects between cohort and country clearly shows that the differences between Germany and Japan did not vanish over historical time, as most of the coefficients show strongly significant results. In the cohorts of 1920 and 1930, entry into a relationship (either marriage or cohabitation) was later in Germany than in Japan; if the educational level of the cohort is held constant, however, the situation is shown to have reversed after 1940. Increasingly, Japanese women entered into marriage at later ages than German women entered into marriage or cohabitation. A similar development is seen for the entry into motherhood, but at a much lower intensity. For the family extension to a third child, a curvilinear trend is revealed. If the educational level (and the expansion of higher education over time) is controlled for, a renewed increase is observed for the youngest 
cohorts. However, as the interaction effects show, the likelihood was higher at all times in Japan than in Germany.

Table 5:

Cohort changes of the family formation processes of women in Japan and Germany

\begin{tabular}{|c|c|c|c|c|c|c|}
\hline \multirow[b]{2}{*}{ Country: Germany ${ }^{1)}$} & \multicolumn{2}{|c|}{ Relationship } & \multicolumn{2}{|c|}{ 1st Birth } & \multicolumn{2}{|c|}{ 3rd Birth } \\
\hline & $1.74 * * *$ & $1.55^{* * *}$ & $1.19 * * *$ & $1.18^{* * *}$ & .96 & $1.25^{* * *}$ \\
\hline Education & $0.57 * * *$ & $0.56^{* * *}$ & $0.48 * * *$ & $0.47 * * *$ & $0.64 * * *$ & $0.64 * * *$ \\
\hline \multicolumn{7}{|l|}{ Cohort } \\
\hline 1920 & $0.72 * * *$ & $1.25 * *$ & $0.73^{* * *}$ & 0.98 & $1.72 * * *$ & $2.97 * * *$ \\
\hline 1930 & $0.80 * * *$ & $1.28 * * *$ & $0.87 * * *$ & 0.99 & $1.21 * * *$ & $1.35 * * *$ \\
\hline 1940 (reference) & 1.00 & 1.00 & 1.00 & 1.00 & 1.00 & 1.00 \\
\hline 1950 & $1.15 * * *$ & 0.98 & $0.92 * * *$ & 0.96 & $0.83 * * *$ & 1.09 \\
\hline 1960 & $1.03 *$ & $0.83 * * *$ & $0.82 * * *$ & $0.77 * * *$ & 0.95 & $1.29 * * *$ \\
\hline 1970 & $0.79 * * *$ & $0.64 * * *$ & $0.67 * * *$ & $0.60 * * *$ & $1.21 * * *$ & $1.29 * * *$ \\
\hline 1980 & $0.53 * * *$ & $0.42 * * *$ & $0.59 * * *$ & $0.46^{* * *}$ & $1.65 * * *$ & $1.68 * *$ \\
\hline Country x 1920 & & $0.53 * * *$ & & $0.71 * * *$ & & $0.47 * * *$ \\
\hline Country x 1930 & & $0.48 * * *$ & & $0.80 * * *$ & & 0.87 \\
\hline Country x 1950 & & $1.26 * * *$ & & 0.94 & & $0.68 * * *$ \\
\hline Country x 1960 & & $1.32 * * *$ & & $1.08^{*}$ & & $0.65 * * *$ \\
\hline Country x 1970 & & $1.32 * * *$ & & $1.16^{* * *}$ & & 0.89 \\
\hline Country x 1980 & & $1.33 * * *$ & & $1.33 * * *$ & & 0.94 \\
\hline
\end{tabular}

Note: ${ }^{1)}$ reference: Japan

The specific role of education in this social change can be seen in the additional results of Table 6 , in which the interaction effects of country (again with Japan as reference), educational level (centred at the 50th percentile) and the year of birth (centred at the median year of birth of all respondents) were calculated as a Cox regression model. 
Table 6:

Education and the family formation process of women in Japan and Germany

\begin{tabular}{llll}
\hline & Relationship & 1st Birth & 3rd Birth \\
\hline Country: Germany ${ }^{1)}$ & $1.82 * * *$ & $1.24 * * *$ & 0.96 \\
Education (centred) & $0.73^{* * *}$ & $0.57^{* * *}$ & 0.94 \\
Year of birth (centred) & $0.98^{* * *}$ & $0.99^{* * *}$ & 1.00 \\
Country x Education & $0.72 * * *$ & $0.75^{* * *}$ & $0.61 * * *$ \\
Country x Year of birth & $1.01 * * *$ & $1.01 * * *$ & 0.99 \\
Year of birth x Education & 0.99 & $0.99^{* *}$ & $1.02 *$ \\
Country x Year of birth x Education & 0.99 & 0.99 & $0.98^{*}$ \\
\hline
\end{tabular}

Note: ${ }^{1)}$ reference: Japan.

\section{Discussion}

Trend hypotheses have always been very popular in the social sciences in general, and in family research in particular. In most cases, these hypotheses describe social change by contrasting what is happening 'now' with what happened in a not very well defined 'past', sometimes with speculation about what trends will dominate in a not very well defined 'future'. A considerable share of social scientists see trend hypotheses as a very important part of their professional product palette, if not its central feature. The problem in this area of research is a lack of criteria for testing trend hypotheses, not to mention a lack of empirical data for doing so. When taken together, this leaves considerable wiggle room for vague argumentation, making attempts to define trends rather speculative, which can hinder scientific progress.

The model of family change and the model of the second demographic transition may be seen as exceptions to this rule. The both make rather clear and falsifiable predictions which compete in some respects, and are thus to some extent mutually exclusive. Both models are also deeply rooted in the general theoretical discourse of their scientific disciplines. The model of family change stems from, and has been most influential on its proponents, in the context of social and cross-cultural psychology. For the model of the second demographic transition, the same is true in the context of social demography. While they deal with the same explananda, so far the two models have not informed each other because of their separate disciplinary backgrounds. However, because they make competing predictions, some criteria can specified that can be used as falsifiers of central assumptions. The comparison of Japan and Germany was chosen for this 
analysis because the two societies have had similar levels of economic development, similar levels and lengths of exposure to the idea of individualisation and similar experiences with regard to the period effects of the Second World War; but different traditions of family culture, with Germans following the north-western European marriage pattern, and the Japanese adhering to the east Asian collectivistic culture. The case of education was used for theoretical and practical reasons. Theoretically, the level of education is a robust proxy measurement for individualisation and increased choices if no other more direct measurements are available. Practically, in the available crosssectional data structures, the causality between education and family formation is clear insofar as the educational career is in almost all cases finished before family formation starts. This is not the case for all indicators related to occupation, income or value measures.

To overcome data problems in the analysis of social change, we chose an approach that differs from the widely used method of interpreting highly aggregated time series was chosen. Instead, we utilised a method that merges the available nationally representative survey data from different time points of collection. This made it possible to establish birth cohorts of women from both societies covering the family formation process from before the Second World War to the beginning of the 21 st century. The advantage of this approach is, in principle, that it solves the macro-micro problem in social science explanations, which cannot be overcome using (highly aggregated) macro-level data alone. More specifically in this case, it allows for the specification of interaction effects, which are crucial for the testing of the competing hypotheses, and which would not be possible with series of aggregate data.

In general, the marriage process in Japan starts significantly later than in Germany (shown by the age differences for the first quartile), is far more standardised than in Germany (shown by the smaller age gap between the first and the third quartiles), and remains more inclusive than in Germany (shown by the lower percentages of never-married women). Thus, the main difference between Japan and Germany is the comparably late, but highly standardised and inclusive entry of Japanese women into marriage, which simultaneously indicates household formation. In contrast, the entry of German woman into a first relatively stable relationship is comparably early, with an increasingly desynchronised process of household formation and marriage, and a decreasing degree of inclusiveness. Differences between both parts of Germany exist, but only as small variations within this general pattern. On the one hand, Japan and Germany differ in all of the observed cohorts with regard to the inclusion into the family formation process and with regard to its timing in the life course; on the other hand, social change in both societies is moving towards higher levels of childlessness and postponement of parenthood. With regard to the research question on family formation processes, the results are ambivalent. While the high degree of standardisation of (late) marriage and the higher rates of inclusion into 
marriage in Japan may be taken as an indication that there are stable cultural differences between the two societies, the increased proportions of never-married women in both societies support the assumptions of the second demographic transition.

The results of the family extension analysis are also mixed. Germany, but not Japan, shows a change in the transition to the second child, a result that fully supports the assumptions of the model of family change. With regard to the transition to the third child, however, the societies seem to converge. After a decline in third births among the older cohorts (probably due in part in both societies to war-related difficulties in finding a partner), the younger cohorts show a moderate recovery for those women who had already extended their family. However, in both societies this slight recovery does not appear to constitute an increase in general fertility, as the percentages of women at age 40 with a third child are continuously decreasing in Japan, as well as in East and West Germany. This latter development may be seen as an indication of support for the assumptions of the second demographic transition.

The increasing differences in the family formation process between educational strata after the 1940 cohort supports the assumptions of the SDT model with regard to the growing role of individualisation in the family formation process. However, the results show enormous differences between Japan and Germany, with family formation by women of both higher and lower educational groups being much more standardised in Japan than in Germany, where women show a much higher degree of variability in the family formation process at all times. Higher education systematically delays first cohabitation or marriage and entry into motherhood in both countries, but has no significant effect on the probability of a third birth after a second child has been born. This delaying effect of education is stronger in Germany than in Japan. Accordingly, a more pronounced trend towards the standardisation of family formation and family extension is noticeable for Japan across the educational levels, as a highly significant interaction effect is found for all three events. This challenges the SDT model and supports the MFC presumption of stable differences between individualistic and collectivistic cultures. Contrary to the predictions of the model of the second demographic transition, the general tendency is that the differences in the family formation process between Japanese and German women have grown over time.

The general conclusion from the empirical analysis is thus not as onedimensional as the competing models suggest. The model of the second demographic transition is verified insofar as the changes occurring in both societies point in the same predicted direction. Entry into relationships and parenthood is delayed, and the proportion of individuals who have never married or had children has increased in both societies. But this does not result in a convergence of the two societies, because social change occurs from different starting points, proceeds at different intensities and speeds, and thus produces 
different outcomes - and, ultimately, increased level differences - at least for the time period under observation. It is more than plausible to attribute these differences in social change to the differences in the cultures of individualism and psychological relatedness, as the model of family change suggests.

The special cases of Japan and Germany also demonstrate quite clearly that theories of value change, such as the SDT and the MFC, have to be complemented by structural theories that take into account the respective opportunity structures for the realisation of value-driven changes in preferences. Both countries were facing the consequences of the Second World War for the partnership and marriage market, which resulted in a shortage of men in specific cohorts, and in turn reduced the opportunities for women to realise their intended family formation processes. Only the interplay of opportunities and preferences can actually explain behavioural outcomes.

Although the empirical analysis goes beyond the usual strategy of inspecting aggregated time series, it still has limitations, and is to some extent only an indirect test of the two competing models. One of the core assumptions of both models is that the family formation process is a result of changes in individual basic values, which result in specific preferences regarding family formation. In the case of the model of family change, affluence is the motor of a transition from economic interdependence to psychological relatedness within collectivistic cultures. For the model of the second demographic transition, the worldwide diffusion of individualisation and the realisation of higher order needs is the driving force. Thus, a full test of the two models has to take into account that cohort effects within societies and educational expansion have only indirect effects on family formation processes via individual values and action preferences. Therefore, a full test would involve taking individual attitudes and their effects on family formation choices explicitly into account, mediating between culture, cohort and education on the one hand, and family formation processes on the other. Undertaking a full test of this kind on the empirical basis of merged survey data is a challenge for the future. This test may rely on the stability of preferences over the life course, using cross-sectional data of respondents who have already realised (some parts of) their family formation process, or it may use methods of data matching to simulate the family formation process of different cohorts. Alternatively, in the best-case scenario, the test would use panel data, which are, however, not available at this point in time.

\section{References}

Alt, C. 1991. „Stichprobe und Repräsentativität.“ In Die Familie in Westdeutschland. Stabilität und Wandel familialer Lebensformen, ed. H. Bertram, 497-532. Opladen: Leske \& Budrich.

Ariès, P. 1980. „Two Successive Motivations for the Declining Birth Rate in the West.” Population and Development Review 6: 645-650. 
Atoh, M. 2001. "Very Low Fertility in Japan and Value Change Hypotheses." Review of Population and Social Policy 10: 1-21.

Atoh, M. 2008. "The Relevance of Ideational Changes to Family Transformation in Postwar Japan." In International Family Change. Ideational Perspectives, ed. R. Jayakody, A. Thornton and W. Axinn, 223-250. New York: Lawrence Erlbaum Associates.

Atoh, M., V. Kandiah and S. Ivanov. 2004. "The Second Demographic Transition in Asia? Comparative Analysis of the Low Fertility Situation in East and South-East Asian Countries." Japanese Journal of Population 2: 42-75.

Bender, D., W. Bien and C. Alt. 1996. Anlage des Familiensurvey, Datenbasis und methodische Aspekte. In Familie an der Schwelle zum neuen Jahrtausend. Wandel und Entwicklung familialer Lebensformen, ed. W. Bien, 271-291. Opladen: Leske \& Budrich.

Blossfeld, H.P. and J. Huinink. 1991. „Human Capital Investments or Norms of Role Transition? How Women's Schooling and Career Affect the Process of Family Formation." American Journal of Sociology 97: 143-168.

Blossfeld, H.P. and U. Jaenichen. 1992. "Educational Expansion and Changes in Women's Entry into Marriage and Motherhood in the Federal Republic of Germany." Journal of Marriage and the Family 54: 302-315.

Caldwell, J.C. 1982. The Theory of Fertility Decline. London/New York: Academic Press.

Coleman, D. 2004. "Why we don't have to believe without doubting in the "Second Demographic Transition" - some agnostic comments." Vienna Yearbook of Population Research 2004(2): 11-24.

Department of Social Structure Research. 1998. The 2nd Survey of Japanese Family Households Report. Tokyo: National Institute of Population and Social Security Research.

Diekmann, A. 1990. "Der Einfluß schulischer Bildung und die Auswirkungen der Bildungsexpansion auf das Heiratsverhalten." Zeitschrift für Soziologie 19: 265-277.

Durkheim, E. 1978. "The conjugal family." In Emile Durkheim on Institutional Analysis, ed. M. Traugott, 229-239. Chicago: University of Chicago Press.

Goode, W.J. 1963. World Revolution and Family Patterns. New York: Free Press.

Goode, W.J. 1993. World Changes in Divorce Patterns. New Haven, London: Yale University Press.

Huinink, J., J. Brüderl, B. Nauck, S. Walper, L. Castiglioni and M. Feldhaus. 2011. "Panel Analysis of Intimate Relationships and Family Dynamics (pairfam). Conceptual framework and design." Zeitschrift für Familienforschung 23: 77-101.

Huinink, J. and M. Wagner. 1995. "Partnerschaft, Ehe und Familie in der DDR." In Kollektiv und Eigensinn. Lebensverläufe in der DDR und danach, ed. J. Huinink, K. U. Mayer, M. Diewald, H. Solga, A. Soerensen and H. Trappe, 145-188. Berlin: Akademie Verlag.

Infratest Sozialforschung. 2000. Familie und Partnerbeziehungen in der Bundesrepublik Deutschland. Familiensurvey 2000. Methodenbericht. München: Infratest.

Kağıtçıbaşı, C. 2005. "Autonomy and Relatedness in Cultural Context. Implications for Self and Family." Journal of Cross-Cultural Psychology 36: 403-422.

Kağıtçıbaşı, C. 2006. "Theoretical perspectives on family change.” In Families Across Cultures. A 30-Nation Psychological Study, ed. J. Georgas, J.W. Berry, F.J.R. van de Vijver, C. Kağıtçıbaşı and Y.H. Poortinga, 72-89. Cambridge, UK: Cambridge University Press. 
Kağıtçıbaşı, C. 2007. Family and Human Development Across Cultures. A View From the Other Side. Mahwah, NJ: Erlbaum.

Kaneko, R., T. Sasai, S. Kamano, M. Iwasawa, F. Mita and R. Moriizumi. 2008. „Marriage Process and Fertility of Japanese Married Couples.” Japanese Journal of Population 6: 24-50.

Klein, T. 1995. „Heiratsmarkt und 'Marriage Squeeze'“ ' In Familie im Brennpunkt von Wissenschaft und Forschung, ed. B. Nauck and C. Onnen-Isemann, 357-368. Neuwied/ Kriftel: Luchterhand.

Klein, T. 2003. „Die Geburt von Kindern in paarbezogener Perspektive.“ Zeitschrift für Soziologie 32: 506-527.

Kravdal, O. and R. Rindfuss. 2008. "Changing Relationships between Education and Fertility: A Study of Women and Men Born 1940 to 1964." American Sociological Review 73: 854-873.

Kreyenfeld, M. and J. Huinink. 2003. "Der Übergang zum ersten und zweiten Kind. Ein Vergleich zwischen Familiensurvey und Mikrozensus." In Partnerschaft und Familiengründung. Ergebnisse der dritten Welle des Familien-Survey, ed. W. Bien and J.H. Marbach, 43-64. Opladen: Leske \& Budrich.

Kumagai, F. 2008. Families in Japan. Changes, Continuitiers, and Regional Variations. Lanham: University Press of America.

Leipziger Institut für empirische Forschung. 1991. Familie und Partnerbeziehung in der Bundesrepublik (Ost). Methodenbericht zur Datenerhebung 1990/91. Leipzig.

Lerner, D. 1958. The Passing of Traditional Society: Modernizing in the Middle East. Glencoe, IL: Free Press.

Lesthaeghe, R. 1983. "A Century of Demographic and Cultural Change in Western Europe: An Exploration of Underlying Dimensions." Population and Development Review 9: 411-435.

Lesthaeghe, R. 2010. "The Unfolding Story of the Second Demographic Transition." Population and Development Review 36(2): 211-251.

Lesthaeghe, R. and J. Surkyn. 2008. "When History Moves On: The Foundations and Diffusion of a Second Demographic Transition." In International Family Change. Ideational Perspectives, ed. R. Jayakody, A. Thornton and W. Axinn, 81-117. New York: Lawrence Erlbaum.

Maslow, A. 1954. Motivation and Personality. New York: Harper \& Row.

Mayer, K.U. 2007. "Retrospective Longitudinal Research: The German Life History Study." In Handbook of Longitudinal Research: Design, Measurement and Analysis, ed. S. Menard, 85-106. San Diego: Elsevier.

Naderi, R., D. Jürgen and K. Ruckdeschel. 2009. „Einleitung - Der Generations and Gender Survey in Deutschland: Zielsetzung, Verortung, Einschränkungen und Potenziale." Zeitschrift für Bevölkerungswissenschaft 34: 5-30.

Nauck, B. 2007. "Value of Children and the Framing of Fertility: Results from a Crosscultural Comparative Survey in 10 Societies." European Sociological Review 23(5).

Nauck, B. 2009. "One or two pathways to modernity? A systematic comparison of Kağıtçıbaşı's Model of Family Change and the Model of the Second Demographic Transition." In Perspectives on Human Development, Family, and Culture, ed. S. Bekman and A. Aksu-Koc, 209-226. Cambridge: Cambridge University Press.

Nazio, T. and H.P. Blossfeld. 2003. "The diffusion of cohabitation among young women in West Germany, East Germany and Italy." European Journal of Population-Revue Europeenne De Demographie 19(1): 47-82. 
Nishioka, H., Y. Koyama, A. Hoshi and S. Shirahase. 2010. "The Family Changes in Contemporary Japan: Overview of the Results of the Third National Survey on Family in Japan (2003)." Japanese Journal of Population 8(1): 1-33.

Nishioka, H., M. Yamauchi, Y. Koyama, Y. Chitose, S. Kamano, K. Suga and A. Hoshi. 2012. "The Family Changes in Contemporary Japan: Overview of the Results of the Fourth National Survey on Family in Japan (2008)." Japanese Journal of Population, 10(1): 1-31.

Raymo, J.M. and M. Iwasawa. 2005. "Marriage Market Mismatches in Japan: An Alternative View of the Relationship between Women's Education and Marriage." American Sociological Review 70: 801-822.

Rindfuss, R.R., M.K. Choe, L.L. Bumpass and N.O. Tsuya. 2004. "Social Networks and Family Change in Japan." American Sociological Review 69: 838-861.

Ruckdeschel, K., A. Ette, G. Hullen and I. Leven. 2006. Generations and Gender Survey. Dokumentation der ersten Welle der Hauptbefragung in Deutschland. Wiesbaden: Bundesinstitut für Bevölkerungsforschung.

Shirahase, S. 2000. "Women's Increased Higher Education and the Declining Fertility Rate in Japan." Review of Population and Social Policy 9: 47-63.

Sobotka, T. 2008. "The diverse faces of the Second Demographic Transition in Europe." Demographic Research 19: 171-224.

Strohmeier, K.P. and J. Huinink. 2003. "Germany." In International Encyclopedia of Marriage and Family, ed. J.J. Ponzetti, 735-743. New York: Macmillan.

Surkyn, J. and R. Lesthaeghe. 2004. "Value Orientations and the Second Demographic Transition (SDT) in Northern, Western and Southern Europe: An Update." Demographic Research 3(Special Collection): 45-86.

Suzuki, T. 2006. "Fertility Decline and Policy Development in Japan." Japanese Journal of Population 4: 1-32.

Takahashi, S. 2004. "Demographic Investigation of the Declining Fertility Process in Japan.” Japanese Journal of Population 2: 93-116.

Thornton, A. 2005. Reading History Sideways. The Fallacy and Enduring Impact of the Developmental Paradigm on Family Life. Chicago: University of Chicago Press.

van de Kaa, D.J. 1987. "Europe's Second Demographic Transition.” Population Bulletin 42.

van de Kaa, D.J. 2003. „The Idea of a Second Demographic Transition in Industrialized Countries." Journal of Population and Social Security 1: 1-34.

van de Kaa, D.J. 2004. "Is the Second Demographic Transition a useful research concept? Questions and answers." Vienna Yearbook of Population Research 2004(2): 4-10. 